Indeed, a change in the BMX bike design to prevent the wide handlebars turning through $90^{\circ}$ and thereby being in direct line with the abdomen-as is the case with most conventional bikes-may be sensible.

ANTHONY SPARNON Our Lady's Hospital for Sick Children, Dublin 12

1 Sparnon T, Moretti K, Sach RP. BMX handlebarA threat to manhood? Med $\mathcal{F}$ Aust 1982;ii:587-8. Burk AM. A serious BMX bike injury. Med $\mathcal{f}$ Aus
1982;ii:283.

SIR,-We also have found an increase in the severity of bicycle injuries related to the BMX bicycle as against the ordinary bicycle. In particular we have seen several mandibular condyle fractures ${ }^{1}$ and some severe facial lacerations. The children injured on $B M X$ bikes were younger on average than the children injured on ordinary bicycles. So far none of the injured children we have been asked to see with BMX bicycle injuries has worn protective clothing, gloves, helmet, etc. Most accidents related to stunts and did not involve a third party. I believe it would be in the industry's interest to ensure that parents know of the hazards and that BMX bicycles should be sold with protective clothing included.

David M Adlam

Maxillofacial Unit, Glan Clwyd Hospital,
Rhyl, Clwyd LL18 5 U

1 Adlam DM. Mandibular fractures and the BMX bicycle. Br Dent $\mathcal{f} 1984 ; 156: 430$.

SIR,-I have recently managed a life threatening injury due to the intrinsic mechanical failure of a BMX bike, which has not previously been reported.

A 13 year old boy who had been riding his BMX bike for three years was cycling normally along a public road when the front forks spontaneously sheared just above the level of the fork crown. He was thrown over the front of the bike and sustained a point injury to his abdomen from one end of the loose handlebars. He also sustained minor limb abrasions.

He was admitted to the surgical wards of the Vale of Leven Hospital, Dunbartonshire, within two hours of injury and was found to have symptoms and signs of left sided peritonism-maximal in the left upper quadrant. The only external sign of injury was an abrasion in the left iliac fossa An erect abdominal $x$-ray examination showed little free gas below the right hemidiaphragm.

At laparotomy he had free fluid soiling the peritoneal cavity, and there were two $2.5 \mathrm{~cm}$ diameter perforations of the upper third of the jejunum $12 \mathrm{~cm}$ apart. One was on the antimesenteric border and the other on the mesenteric border associated with a mesenteric haematoma. A $16 \mathrm{~cm}$ length of small bowel was resected, the bowel was reanastomosed, and a tetracycline lavage was performed. The patient made an uneventful recovery and was discharged on the ninth postoperative day.

The bicycle itself had been guaranteed for 10 years, but examination showed that the tube had fractured circumferentially at a level where two internal steel pins held the fork tube within the fork crown. Presumably this had become weakened due to repeated stress from stunts on tarmacadam and concrete surfaces which the bike was not designed to withstand.

Small bowel rupture occurs in 5-10\% of cases of severe blunt abdominal trauma and carries a high mortality if there are multiple injuries or the diagnosis is delayed-as is often the case. ${ }^{1}$ It is uncommon to have an isolated injury of double jejunal perforation, ${ }^{2}$ and most are usually small enough to be oversewn. ${ }^{1}$ In children rupture of the gastrointestinal tract is commonly associated with bicycle accidents, and it has been observed that these may be caused by point injuries from the end of a handlebar. ${ }^{3}$

Without doubt stricter safety and design standards are required to reduce the risk of mechanical failure in some models of BMX bikes, although it is likely that the best bikes on the market are adequately safe at present. A publicity campaign to make parents and children aware of the dangers of stunt riding outside recognised BMX tracks and without adequate protective gear would also be highly desirable. Finally, another possibility could be the introduction of a certificate of riding competence, perhaps issued by BMX organisations, since many of the injuries are occurring in inexperienced riders.

JONATHAN S TUCK

Department of Urology,

\section{Victoria Infirmary,}

1 Robbs JV, Moore SW, Pillay SP. Blunt abdominal trauma with jeju

Geoghan T, Brush BE. The mechanism of intestina perforation from non-penetrating abdomina Dickinson SJ, Shaw A, Santulli TV. Rupture of the gastrointestinal tract in children by blunt trauma.
Surg Gynecol Obstet 1970;130:655-7.

SIR,-We have found BMX bike injuries to be an important problem in our area over the last year. We have reviewed the patients with injuries attributable to BMX bikes who required admission under one surgical team in a one in three on call rota over six months finishing September 1984.

Thirty four children required admission, and 28 had head injuries with a suspected or proved episode of loss of consciousness. There were no skull fractures on radiological examintion. In five cases there were important facial injuries, either cuts or grazes that required further attention. Five cases were admitted because of abdominal trauma, and we thought that further investigation and observation were warranted.

In four of these cases no important pathology was detected, but in one 8 year old boy clinical examination showed a haemotoma in the left upper abdominal quadrant, although there was no break of the skin in this area. Subsequently he developed signs of peritonitis and a laparotomy was performed. This showed a partial rupture of the duodenojejunal flexure with a traumatic rupture of the left rectus abdominal muscle and rectus sheath. In this case the injury had been inflicted by the handlebars of a friend's bike; they had collided while carrying out a stunt riding down a hill. He made an uneventful recovery.

Most patients in this group were aged 5-12 (29 out of 34), and none was older than 16 . In addition, we found that all of these children had been doing some sort of stunt or "reckless manoeuvre" when the injury happened.

These results relate to a select group of patients and obviously take no account of the number of others seen in the casualty department with less severe injuries and orthopaedic problems. The more severe injuries appear to be related to participation in stunts, which compares with the $40 \%$ incidence of stunt related injuries in Dr Cynthia Illingworth's paper.

C R Chapple

Department of Surgery,

Selly Oak Hospital,

Birmingham

\section{Motorcycling injuries in children}

SIR,-We share the concern of Mr K Sherman and $\mathrm{Dr} J$ Mackinnon (6 October, p 877) and Mr M A Mason (p 854) over motorcycling injuries in children, particularly in so far as they affect younger children. As Court put it, accidents "are the result of the encounter of developmentally immature children with a dangerous environment," but there is a world of difference between the physical capabilities and judgment of a 5 or 6 year old and those of an adolescent of 14 or $15 .^{1} \mathrm{Mr}$ Sherman and Dr Mackinnon comment on the "immature skeletons" of the riders, but it is the overall developmental immaturity which is of great importance in producing an accident.

Mr Mason is not correct in saying that "the details that are available relate only to motorcycle accidents occurring on the public highway": short reports by Stilwell in $1978^{2}$ and Place in $1979^{3}$ both looked at scrambling accidents off the roads. Stilwell included accidents in both officially supervised and unsupervised races, while Place's series was of children injured in official races only. Both these authors felt that the injuries were acceptable both in frequency and severity, but in correspondence after Place's paper we disagreed strongly with this and commented "that children under the age of 12 are incapable of making the correct judgments that these circumstances necessitate." Place later agreed that "children of this age are not suited physically or mentally to take part in such sports." 5

It is the children under 13 or so who concern us most. Riding some (but not all) motorcycles demands the simultaneous and precise use of all four limbs to operate accelerator, clutch, brake, and gears. This has to be done at the same time as judging speed and distance, and it must be done reliably. In our opinion, children of 6-11 are developmentally incapable of doing this consistently. The increases in physical strength and coordination that occur with puberty result in a clear cut change over the next few years so that the well developed and coordinate 14 or 15 year old presents a very different range of abilities and is entitled to test himself out.

There appear to be two groups of factors which have led to the use of motorcycles by very young children. The first relates to the parents. Parents' misunderstanding of their children's abilities to cope with traffic is well recognised-Sadler's work showing that $13 \%$ of mothers of children aged only 2 years expect them to be able to cross a main road by themselves in safety is a supreme example ${ }^{6}$-and there is a lack of appreciation of the risks that they expose their children to on motorcycles. In addition, as Place pointed out, parents are encouraging the child "not for his enjoyment but for the feelings of displaced pleasure that they experience." We have heard of a father saying to his crying 6 year old "get back on that bike and don't be so soft."

The second factor is the attitude of the motorcycle manufacturers. We think it reprehensible to make machines specially for young children, and the industry must know the results of the use of these machines. (At the other end of the scale one wonders why motorcycles (or cars) capable of $130 \mathrm{mph}(210 \mathrm{kph})$ are sold when these speeds are illegal.)

What can be done? It may be that more data will be needed. We know of children with severe head injuries (with and without brain damage), gas gangrene, fractured facial bones, and severe leg injuries, but comprehensive data which give information about age, injury, type, and severity, together with place and type of activity are also 
required. This means work for doctors and others and illustrates the vital but often neglected role of doctors in accident prevention.

Though such evidence may be necessary to define the problem in young teenagers, we believe that there is enough knowledge of young children's lack of capability in traffic and sufficient concern over the problem to warrant action being taken. We think that those responsible for organising this sport should show a greater sense of responsibility and, as Dr Mason suggests, should raise the lower age limit for participation from 6 to 13 or 14. If they did this parents would recognise the reasons and would not start their children riding outside official races until they are old enough to ride officially. After all, if officials allow 6 year olds to ride why should ordinary parents do otherwise? If the organising bodies do not take this action voluntarily then legislation may be necessary. We have no doubt that the Parliamentary Advisory Council on Transport safety will be watching this closely.

R H JACKSON

Child Accident Prevention Trust, Lndon WIN 3AL

\section{A W CRAFT}

Department of Child Health,

Royal Victoria Infirmary,
Newcastle upon Tyne NE1 4LP

1 Committee on Child Health Services. Fit for the future. London: HMSO, 1976;1:43. (Court report.) Stilwell JH. Motorcycling scrambling injuries in boys. Br Med $\mathcal{f} 1978 ; i: 758$.

3 Place M. Injuries to boys who scramble. Br Med $\mathrm{f}$ $1979 ; \mathrm{i}: 1322$.

4 Jackson RH, Craft AW. Injuries to boys who scramble. Br Med F 1979;i:1625.

5 Place M. Injuries to boys who scramble. $\mathrm{Br}$ Med $\mathcal{f}$ 1979 ;ii:48.

6 Sadler J. Children and road safety: a survey among mothers. London: HMSO, 1972.

Sir,-Mr M A Mason (6 October, p 854) does well to bring to public notice the high incidence of accidents in children under the age of 16 riding motorcycles. There is, however, another aspect of this current crazenamely, pollution of the atmosphere by noise. Admittedly it has never killed anyone, but I believe that distress is caused to many people, often in rural districts, because of this iniquitous pastime.

The underage rider off the public highway is interested in two things only-speed and noise-and the more of either that he can produce the higher he stands among his peers. The parents of such children generally seem to be indifferent both to the dangers to the child and to the annoyance of anyone in earshot. I believe that the time has come for legislation to raise the lower age limit, restrict the use of these vehicles to certain limited supervised centres, and define upper limits of permissible noise.

F R Goodwin

Sutton Coldfield,

West Midlands B76 9CN

SIR,-The unbridled enthusiasm with which the BBC latched on to this subject is matched only by that of the $B M \mathcal{F}$ for publishing a leading article on a subject about which few data are available. Quite correctly the original article by $\mathrm{Mr} \mathrm{K}$ Sherman and Dr J MacKinnon appeared as a short report-correct because apart from describing a new group of accidents little else of interest emerged.

Why then boost this interesting but otherwise unremarkable set of figures with a leading article that concludes with a demand for legislation. How about demanding some statistically valid information? For example: what percentage of young motorcyclists are involved in these accidents; was the age range evenly spread; and, perhaps more relevant, how does the accident rate compare with other juvenile risk activities such as horseriding, cycling, rollerskating, skateboarding, skiing, climbing trees, and even football ?

Dr M A Mason's leading article was not even logically argued-for if, indeed, many more children ride motorcycles unsupervised than in recognised clubs then the fact that the unsupervised group provided only half of the accident cases would seem to support the outlawing of supervised riding, and not the reverse-clearly a nonsensical conclusion, or is it?

Finally, BMX bike injuries seem to present a problem of apparently greater magnitude than motorcycle injuries. Can we now expect a call to have these machines outlawed?

Chepstow,

K J J TAYTON

Gwent NP6 6HW

How common are risk factors among young patients suffering heart attacks?

SIR,-Professor M F Oliver (7 July, p 50) states that young patients with acute myocardial infarction are commonly found "without any measurable risk factors." Over 16 years since 1966 we have seen 795 successive men under 60 who have had their first myocardial infarction at this hospital and have survived 28 days. The table records their distribution into different categories of risk, using standard criteria to identify the three primary risk factors-hyperlipidaemia (serum cholesterol greater than $6.29 \mathrm{mmol} / \mathrm{l},(240$ $\mathrm{mg} / 100 \mathrm{ml}$ ), hypertension, and cigarette smoking. Only $1.8 \%$ of these patients were without any of the three primary risk factors, and the proportion did not alter significantly in the younger age groups.

Can Professor Oliver provide data to support his contention that young patients with myocardial infarction are often encountered with no measurable risk factors?

RISTEARD MULCAHY RONÁN CONROY

Cardiac Department,

St Vincentin

** Professor Oliver replies below.-ED, BMF.

SIR,-Professor Mulcahy and Dr Conroy provide valuable information confirming the frequency of risk factors in survivors of first myocardial infarction: indeed, this may be the first time that the documentation has been so thorough. But their apportioning of the presence or absence of risk factors depends, of course, on the cut off points used. These appear to be arbitrary. If those for hypertension are near the median and smokers of 1-10 cigarettes daily are included we may not be so far apart.

My contention that it is not uncommon to find young patients with myocardial infarction at more normal levels of risk than those used for the analysis by Professor Mulcahy and Dr Conroy is based on an earlier international study of risk factors in nine countries. ${ }^{1}$

Of 240 men aged 40 or less who survived acute myocardial infarction $53 \%$ had serum cholesterol concentrations less than 6.22 $\mathrm{mmol} / 1(240 \mathrm{mg} / 100 \mathrm{ml})$ and only a quarter had cholesterol concentrations of $7.25 \mathrm{mmol} / 1$ $(280 \mathrm{mg} / 100 \mathrm{ml})$ or more; $79 \%$ had systolic blood pressures equal to or less than 158 $\mathrm{mm} \mathrm{Hg}$, and $74 \%$ had diastolic blood pressures less than $90 \mathrm{~mm} \mathrm{Hg} ; 30 \%$ either did not smoke or smoked less than 15 cigarettes a day; $81 \%$ were not obese (Quetelet's index >0.28); $92 \%$ did not have a diabetic glucose tolerance response; and $83 \%$ did not have hyperuricaemia (>0.5 mmol/1 $(8.4 \mathrm{mg} / 100 \mathrm{ml})$ ).

This international study also showed that the prevalence of risk factors varies considerably between countries, and it should not be assumed that the high frequency found in survivors of myocardial infarction in Ireland applies equally in all communities.

\section{F OLIVER}

\section{Cardiovascular Research Unit,}

Edinburgh EH8 9XF

1 Dolder MA, Oliver MF. Myocardial infarction in young men. Study of risk factors in nine countries
Br Heart $\mathcal{F} 1975 ; 37: 493-503$.

\section{Neuroleptic malignant syndrome induced by a single injection of haloperidol}

SIR,-Dr E Szabadi has reviewed the causes and treatment of the neuroleptic malignant syndrome (12 May, p 1399). We describe a case of the neuroleptic malignant syndrome following a single injection of haloperidol and a therapeutic trial with dantrolene sodium.

A 58 year old woman was admitted to our ward because of ileus. She had undergone two laparotomies 10 months and four months previously for adenocarcinoma of the endometrium and had received postoperative radiotherapy. On admission she was well orientated and cooperative, and we decided to operate on her. The night before the operation the patient received a single intramuscular injection of $5 \mathrm{mg}$ haloperidol as a tranquilliser.

The following morning she was confused and developed sinus tachycardia $(140 / \mathrm{min})$ and hyperthermia (above $40^{\circ} \mathrm{C}$ ) accompanied by muscle rigidity and opisthotonos. A lumbar puncture was performed and showed normal sterile cerebrospinal fluid. Serological tests, blood and urine cultures, and a tuberculin test were negative.

Distribution of 795 men who survived their first myocardial infarctions under 60 years into different risk categories

\begin{tabular}{lccccc}
\hline Age & $\begin{array}{c}\text { No risk factors } \\
\text { No }(\%)\end{array}$ & $\begin{array}{c}\text { One risk factor } \\
\text { No }(\%)\end{array}$ & $\begin{array}{c}\text { Two risk factors } \\
\text { No }(\%)\end{array}$ & $\begin{array}{c}\text { Three risk factors } \\
\text { No }(\%)\end{array}$ & $\begin{array}{c}\text { Number of cases } \\
\text { No }(\%)\end{array}$ \\
\hline Under 60 & $14(1 \cdot 8)$ & $260(32 \cdot 7)$ & $403(50 \cdot 7)$ & $118(14 \cdot 8)$ & $795(100)$ \\
Under 50 & $5(1 \cdot 5)$ & $101(30.7)$ & $174(52 \cdot 9)$ & $49(14 \cdot 9)$ & $329(41 \cdot 4)$ \\
Under 45 & $2(1 \cdot 4)$ & $42(28 \cdot 4)$ & $81(54 \cdot 7)$ & $23(15 \cdot 5)$ & $148(18 \cdot 6)$ \\
Under 40 & & $25(37.9)$ & $30(45 \cdot 5)$ & $11(16 \cdot 7)$ & $66(8 \cdot 3)$ \\
Under 35 & & $7(43 \cdot 8)$ & $6(37 \cdot 5)$ & $3(18 \cdot 8)$ & $16(2 \cdot 0)$
\end{tabular}

Correlation between age and number of positive risk factors: Tau $=0.038, n=795$, NS. 